Article

\title{
Intelligent Supply Chain Information System Based on Internet of Things Technology under Asymmetric Information
}

\author{
Yunshan Zhou * and Xiangjun Xu \\ Information Center, Zhejiang Business Technology Institute, Ningbo 315012, China; beauty7572@163.com \\ * Correspondence: zhyuns@sina.com
}

Received: 15 March 2019; Accepted: 28 April 2019; Published: 10 May 2019

check for updates

\begin{abstract}
The hardware and software designed in the traditional supply chain system lack cooperation in the transmission process, have low efficiency, and lead to a large amount of information distortion. In response to this problem, this paper proposes an intelligent supply chain information system based on the Internet of Things technology. The research focuses on the hardware and software of the system. The hardware part consists of the embedded processor CS89712, Flash7861 memory, Ethernet, touch screen, and LCD (Liquid Crystal Display). The software system is based on asymmetric information theory design and is divided into signal acquisition, input signal detection, interference signal processing, and power signal output. The experimental results show that it is compared with the traditional supply chain information system. The designed system seamlessly integrates the hardware and software components to achieve maximum information supply in the shortest amount of time. The power supply capacity is four times that of the traditional system, and the node coverage is high. When the number of data nodes is 120 , the traditional supply chain system is basically unable to supply, but the supply accuracy of the intelligent supply chain is still as high as $48 \%$. The research in this paper has certain guiding significance for intelligent technology development, supply chain system design, and enterprise information exchange.
\end{abstract}

Keywords: asymmetric information theory; Internet of Things technology; intelligent technology; communication technology; supply chain information system; embedded microprocessor; intelligent system; Ethernet

\section{Introduction}

Asymmetric information refers to information owned by some parties, but not by others. The theory was proposed in 1970, and American economists Joseph Stiglitz, George Akerlof, and Michael Spence conducted an in-depth research. Under market economy conditions, buyers and sellers of the market cannot fully access the other party's information. This asymmetry of information will inevitably lead to the damage of the interests of one side for the gain of the other [1]. A supply chain system is an integration of key business processes and relationships of an enterprise that provides goods, services, or information to an end customer, from the original material supplier to the entire chain of end users [2]. Asymmetric information theory is decentralized control and centralized management, which is first used in Economics and now in all fields, especially in the field of network technology.

As an extension of the Internet, the Internet of Things not only enables people to communicate with each other but also enables interaction between things [3]. The Internet of Things can also be regarded as an information carrier such as the Internet and traditional telecommunication networks. In the Internet of Things, all ordinary objects that can perform independent functions can be connected to each other and communicate with each other. After entering the 21st century, the Internet of 
Things has become an important part of the new generation of information technology, which is called the Internet with connection between things. Although the Internet of Things is an expanding network of the Internet, the core and foundation is still the Internet. It is only the extension and expansion of users to goods. The Internet of Things has the characteristics of dynamics, integration, and autonomy. As a distributed sensor network, it can flexibly include external information and connect to the Internet through wireless and wired ways, thus forming a multi-hop and self-organizing network. In the Internet of Things, the real world is digital. As long as an electronic tag is attached to an object, its specific location can be found out. By collecting small data to form big data, it plays a major role in reducing traffic accidents, urban renewal, disaster prediction, crime prevention and control, and epidemic control. The Internet of Things can achieve industrialization and automation [4]. With the continuous development of automation in modern large-scale industrial production and the increasing complexity of process-control requirements, intelligent supply chain information systems are the future. The essence of intelligence cannot be independent of data analysis and optimization technology. Data analysis and optimization is one of the key technologies of the Internet of Things, which is also the key to the future value of the Internet of Things. The Internet of Things integrates asymmetric information theory into technology updates. According to all monitored information, the optimal supply method is found through analysis and optimization technology.

Kai et al. [5] proposed a three-tier supply chain problem in which multiple suppliers, one manufacturer, and one retailer were involved. The manufacturer selects the supplier and estimates the number of defective components purchased from the supplier, but due to information asymmetry, the quality information is not available to the manufacturer. However, the customer's needs cannot be accurately predicted. Gou et al. [6] proposed that the Internet of Things technology uses radio frequency equipment, sensors, and wireless sensor networks to establish data acquisition, transmission, and storage systems for various departments of shipbuilding. The manufacturing process is moving toward an intelligent and informational direction. The entire manufacturing cycle includes multiple processes, such as design management, production control, supply chain management, environmental monitoring, etc. The intelligent manufacturing platform based on Internet of Things technology stores and shares information uniformly, but the system has low information coverage. Gong et al. [7] proposed to combine the electronic information technology such as the Internet of Things and the Internet with supply chain management and modern logistics technology, to strengthen the participation of various entities in information interaction and supply chain activities, and help realize the real-time supervision of pledges in the warehouse, in transit, and in processing. The proposed integration of the supply chain financial logistics supervision system, and the pledge of transforming a financial lending system into a supply chain financial logistics operation management platform help to better promote the smooth development of supply chain financial logistics activities, but the system supply accuracy is low.

In this paper, an intelligent supply chain information system based on the Internet of Things technology is designed.

First, the architecture of the embedded processor CS89712 is analyzed, the supply chain connection mode is designed, and the power supply of the system is redesigned.

Second, the software flow of the intelligent supply chain information system is designed, and the software algorithm and the structure model are designed.

Finally, a simulation experiment is established, and the feasibility of the system is verified by experiments.

\section{Hardware Design of the Intelligent Supply Chain Information System}

The intelligent supply chain information system hardware introduced in this paper includes the embedded processor CS89712, supply chain connection mode, and power supply design [8]. By designing the intelligent supply chain information system hardware, the amount of information collected in the supply chain information can be improved. The internal main device is an ARM 
(Advanced RISC Machine) embedded microprocessor. The processor has the features of scalable architecture, low power consumption, low cost, and real-time multitasking support. It is the first choice for designing an intelligent information supply chain system and also a standard chip for Internet of Things technology.

The rapid development of information technology has changed people's daily life. Intelligent systems also need the interconnection of networks [9]. When applying intelligent systems, we should focus on their network characteristics, especially the open TCP/IP (Transmission Control Protocol/Internet Protocol) network. This paper mainly introduces the design and development of chip-level hardware [10]. The ARM embedded processor is not only widely used and powerful but also able to build friendly a human-machine interface and allow high-speed data acquisition [11]. The nature of Ethernet communication makes the hardware have more advantages in communication and realizes the structural and modular design idea. The internal structure of the hardware platform and the division of labor are clear. It can provide a universal hardware platform for the development of an intelligent supply chain with different functions.

The hardware architecture of intelligent supply chain information system based on the Internet of Things is shown in Figure 1.

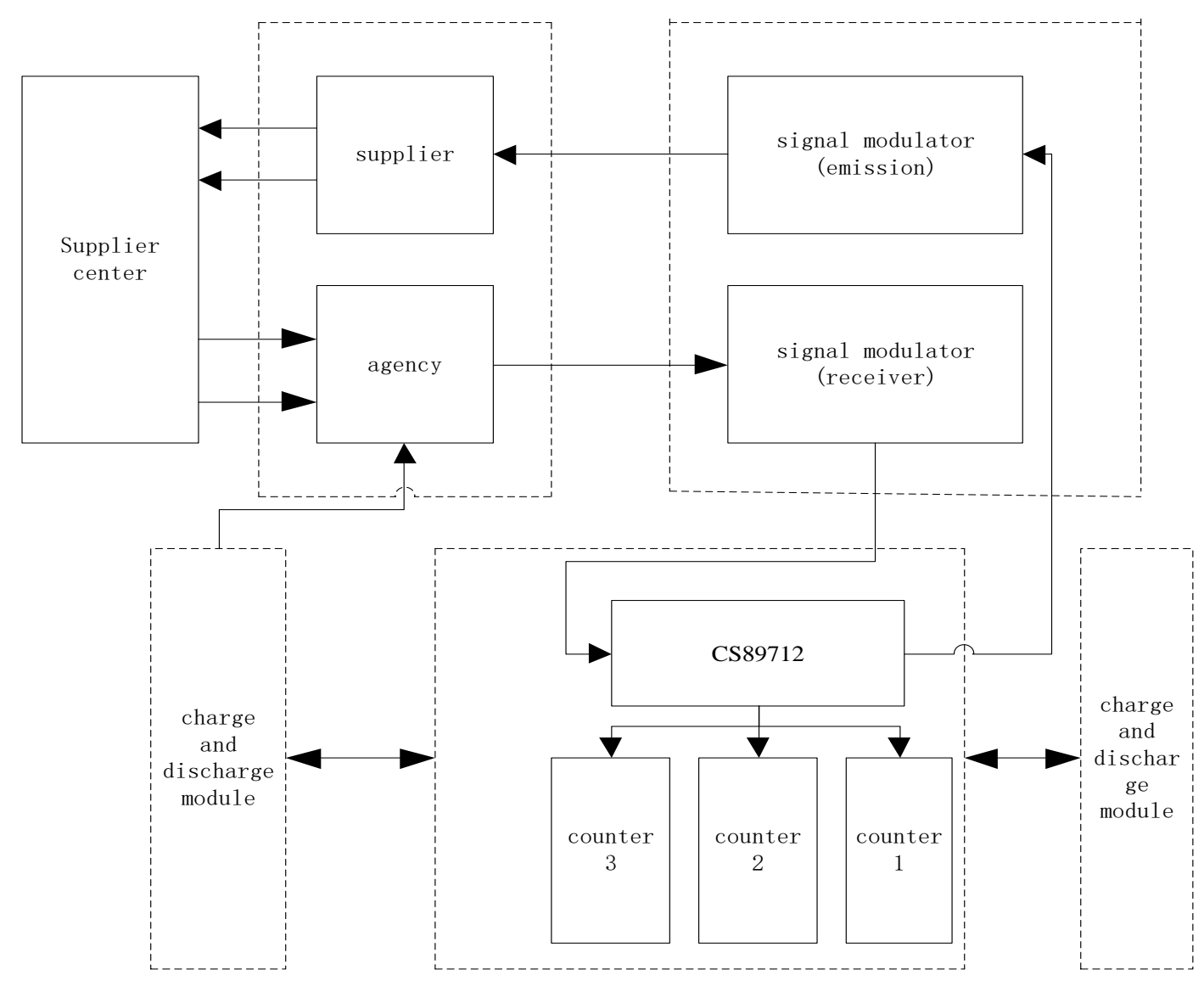

Figure 1. Hardware architecture of intelligent supply chain information system based on Internet of Things technology.

Under the environment of the Internet of Things, all parts of the hardware structure constructed can be linked and work together to set up the initial conditions of the Internet signal. In addition, the hardware part sets the tracking signal. Through the dynamic tracing of supply signals, the whole process of secrecy is completed [12]. The integration of independent and shared technologies provides strong technical support for the continuous and stable operation of the hardware system. The following is a detailed description and introduction of the hardware devices. 


\subsection{The Architecture of the Embedded Processor CS89712}

The embedded processor CS89712 is a 16/32 bit microprocessor produced by the Cirrus Logic Company. The processor core uses a high-performance 32 bit RISC (Reduced Instruction Set Computer) structure with extremely low power consumption. The designed SOC (System on Chip) chip assists in handling the CS89712's work [13]. The core logic function of the chip is built around the ARM720T processor [14]. With 81 bytes and 4 channels, a unified cache and write buffer is set up, and 64 TLB (Translation Lookaside Buffer) inputs are integrated. It has the following features:

(1) Dual power supply, the core voltage is $2.5 \mathrm{~V}$, and multiple clocks can be set, such as $18,36,49$, and $74 \mathrm{MHz}$.

(2) Rich peripheral interface, integrating SDRAM (Synchronous Dynamic Random Access Memory) controller, supporting four internal memory blocks. The memory interface can be programmed. The bit width is from 0 to 32 bit. It also has 8/16/32 bit SRAM (Static Random Access Memory)/Flash/ROM (Read Only Memory) interface.

(3) Integrated LCD (Liquid Crystal Display) controller. It can directly interface with a single-scan board monochrome LCD.

(4) Integrated LOM (Learning Object Meta-data) Ethernet controller (CS8900A), two compatible 16550 UARTs (Universal Asynchronous Receiver/Transmitter).

(5) Built-in 48I, SRAM connection system.

(6) Complete JTAG (Joint Test Action Group) boundary scan and embedded ICE (In-Circuit Emulator).

(7) Supports the Windows operating system.

\subsection{Design of the Supply Chain Connection Mode}

The connection between the embedded processor CS89712 and the intelligent supply chain of the Internet of Things is shown in Figure 2.

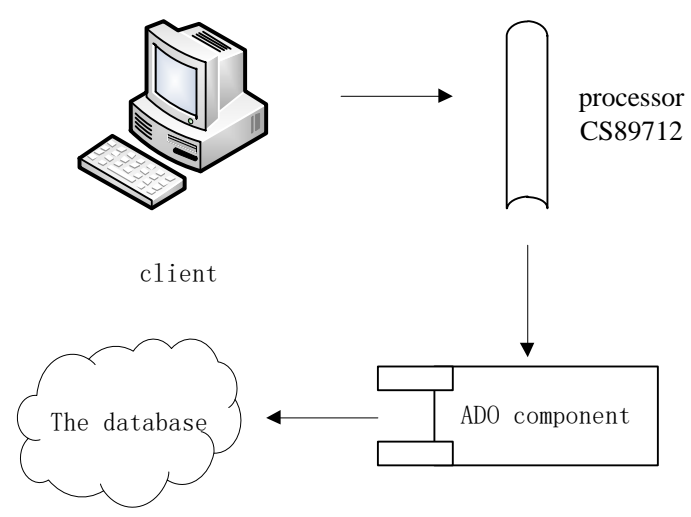

Figure 2. Supply chain connection pattern diagram.

From Figure 2, it can be known that, the Internet of Things connects the processors in the supply chain through Information Technology. There were a large number of IT information nodes in the supply chain that did not participate in the circulation process and were specialized in information services. These nodes could be an independent organizational unit and also provide an independent or co-owned information system for the supply chain [15]. The application of IT in the supply chain helped realized the transformation of the supply chain information transfer from paper documents to computer-based communication networks [16]. The channel of information transmission also changed from the traditional linear mode of single point to single point to the network mode of multi-point to multi-point, which promotes information sharing among the members of the supply chain [17]. In the supply chain, there are centralized information nodes that can be directly linked to all nodes [18]. For the centralized information structure of information nodes centered on manufacturers, the supply 
chain information flow line is from the manufacturer to the supplier/seller. Meanwhile, the physical structure of the supply chain is still hierarchical. The logistics line is: Producer to middleman to supplier/distributor [19]. Therefore, the information flow of the supply chain is not synchronized with the logistics, and the information structure and physical structure are different. IT promoted the separation of the physical structure and the information structure of the supply chain and made it possible to separately optimize both [20].

The information structure of the supply chain was divided into a hierarchical structure, a centralized information structure, and a centralized information structure based on the IT information nodes. The change of the supply chain line is shown in Figure 3.

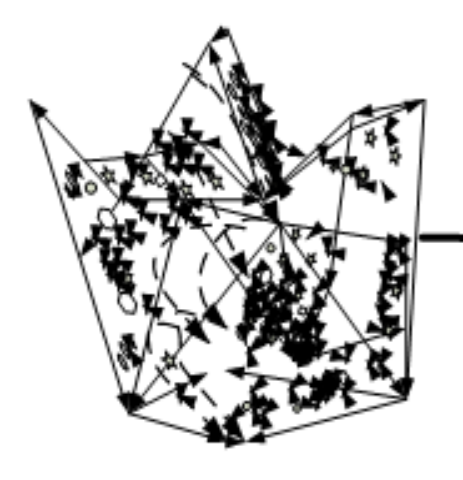

(a)

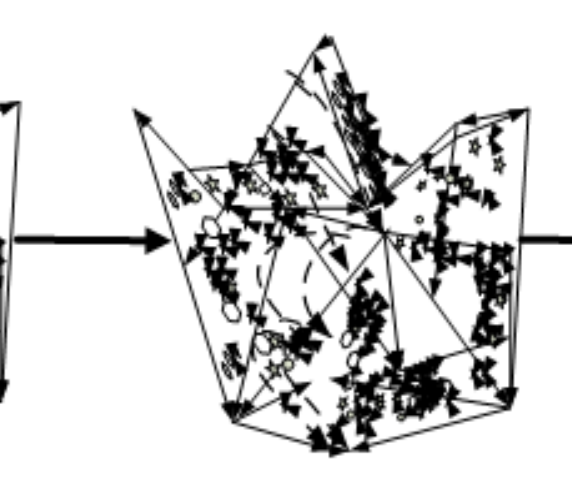

(b)

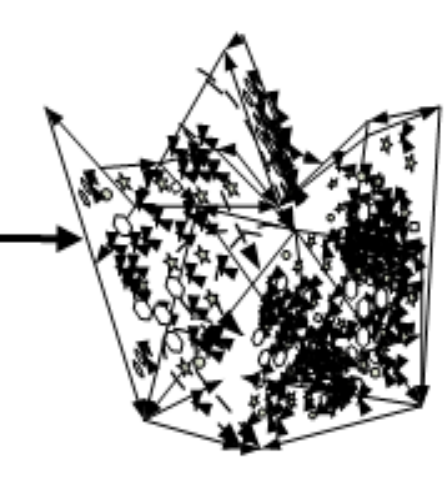

(c)

Figure 3. Change of the supply chain line. (a) A hierarchical structure, (b) a centralized information structure, and (c) a centralized information structure for Information Technology information nodes.

As shown in Figure 3, arrowheads are the information being converted, circles represent worthless information, and stars represent useful information. By replacing the supply line, the degree of inclusion of the information was greatly expanded and the information content was more comprehensive.

\subsection{Design of the Power Supply}

The design process of the power supply was divided into three steps. (1) The voltage of 220V was bucked, rectified, and filtered to obtain a relatively stable DC voltage. (2) The DC voltage was changed and as mooth DC output was obtained after being boosted by the boost chopper circuit and filtered. (3) The UC3843 emitted a PWM (Pulse Width Modulation) signal to drive the switch tube to control the closed-loop feedback [21].

In the research, the voltage divider was adjusted to stabilize the output voltage between 30 and $36 \mathrm{~V}$. When the output voltage was increased, the output of the error amplifier increased after the feedback signal was compared with the reference voltage, thus the output pulse width was narrowed and shortened. The switching time of the switch tube was shortened, thereby reducing the output voltage [22]. According to the same principle, when the output voltage was decreased, the output of the error amplifier reduced after the feedback signal was compared with the reference voltage, thus the output pulse width was widened. The switching time of the switch tube was widened, and then the output voltage would rise. Therefore, the final result of closed-loop feedback regulation was to stabilize the output voltage between 30 and $36 \mathrm{~V}$. Additionally, this circuit had an over-current protection function. When the output current was greater than $2 \mathrm{~A}$, the output of the error amplifier would also increase. When the output voltage decreased, current was limited to protect the field-effect transistor. The Power device list is shown as Table 1. 
Table 1. Power device list.

\begin{tabular}{|c|c|c|c|c|c|c|c|}
\hline No. & Category & Model & Packaging Form & Unit & Amount & Location & Manufacturer \\
\hline 1 & $\begin{array}{c}\text { Power } \\
\text { conversion IC }\end{array}$ & DC-DC & SMC & PCS & 1 & $\mathrm{U}_{1}$ & TUY \\
\hline 2 & Chip diode & TA-UV & CMUI & PCS & 1 & $\mathrm{D}_{1}$ & EWA \\
\hline 3 & Chip capacitor & FC-TA & $\mathrm{R}-023$ & PCS & 5 & $\mathrm{C}_{3} / \mathrm{C}_{5} / \mathrm{B}_{4} / \mathrm{T}_{6} / \mathrm{U}_{5}$ & MRS \\
\hline 4 & Chip capacitor & UA-DC & R-006 & PCS & 2 & $\mathrm{R}_{3} / \mathrm{R}_{5}$ & BUIE \\
\hline 5 & Chip capacitor & UV-DX & $\mathrm{R}-403$ & PCS & 3 & $\mathrm{C}_{7} / \mathrm{B}_{2} / \mathrm{L}_{5}$ & YAGER \\
\hline 6 & Chip capacitor & XX-II & R-003 & PCS & 3 & $\mathrm{X}_{1} / \mathrm{X}_{5} / \mathrm{I}_{6}$ & YAGER \\
\hline 7 & Chip capacitor & UE-DC & $\mathrm{R}-851$ & PCS & 4 & $\mathrm{C}_{1} / \mathrm{V}_{9} / \mathrm{B}_{3} / \mathrm{F}_{4}$ & YAGER \\
\hline 8 & Chip resistor & BR-CI & C-042 & PCS & 2 & $\mathrm{C}_{2} / \mathrm{V}_{1}$ & YAGER \\
\hline 9 & Chip resistor & VU-ER & C-031 & PCS & 5 & $\mathrm{C}_{6} / \mathrm{D}_{4} / \mathrm{E}_{5} / \mathrm{T}_{7} / \mathrm{U}_{3}$ & YAGER \\
\hline 10 & Chip resistor & IO-TY & C-038 & PCS & 3 & $\mathrm{D}_{5} / \mathrm{D}_{8} / \mathrm{D}_{2}$ & YAGER \\
\hline 11 & Chip inductor & OB-TY & B-112 & PCS & 6 & $\mathrm{~B}_{1} / \mathrm{B}_{7} / \mathrm{B}_{3} / \mathrm{S}_{3} / \mathrm{S}_{6} / \mathrm{D}_{5}$ & YAGER \\
\hline 12 & Chip inductor & DC-AQ & B-258 & PCS & 5 & $\mathrm{C}_{2} / \mathrm{C}_{6} / \mathrm{C}_{8} / \mathrm{V}_{\mathrm{S}} / \mathrm{C}_{3}$ & YAGER \\
\hline 13 & Chip inductor & UB-ER & B-114 & PCS & 1 & $\mathrm{H}_{6}$ & YAGER \\
\hline
\end{tabular}

The power supply system comprising the power supply and reset circuits, guaranteed reliable system operation. The system reset module provided the CS89712 start signal. The system used the $n$ POR signal as a reset signal and reset chip to generate the reset signal, as shown in Figure 4 . The external power input of the whole system adopted DC 18-36 V. The power supply of the system was more complex and the voltage level was higher. The CS89712 chip I/O and core were powered by 3.3 and $2.5 \mathrm{~V}$, respectively. The extended MAX125 and the LCD display were powered by SV (Set Value). LCD contrast adjustment needs a negative voltage bias, for which the MAX686 chip was selected. The power supply voltage of the operational amplifier of the filter and voltage following circuit in the analog data acquisition MAX125 forward channel was positive and negative $12 \mathrm{~V}$ [23]. The Ericsson DC/DC power module PI and C2131PI were used here to provide isolated positive and negative 12 and +5 V. At the same time, the MIC2211-2.5/3.3BML dual output LDO (Low Dropout Regulator) of Micrel Company was used to provide 3.3 and $2.5 \mathrm{~V}$ for CS89712.

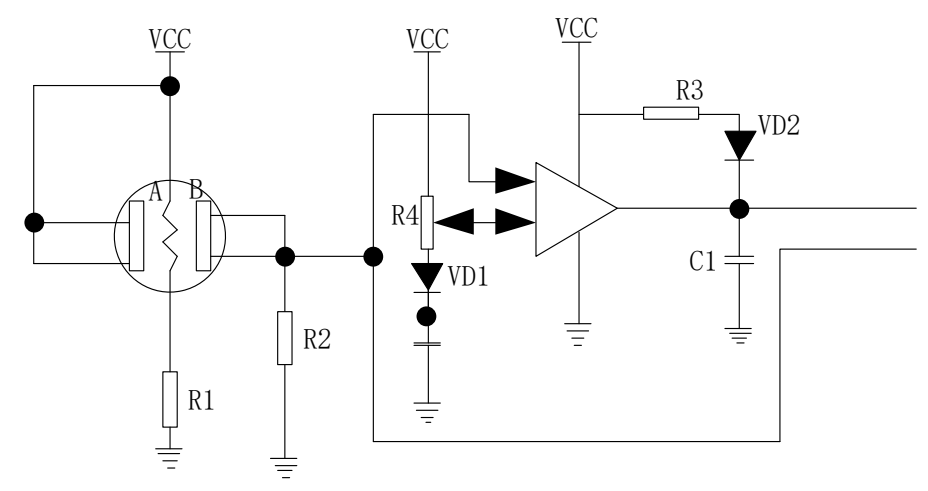

Figure 4. Power schematic diagram.

As shown in Figure 5, in the series circuit, the resistor $R$ is converted, the voltage $U$ is connected, and then the electric power $W$ is input, that is, the circuit model is completed, converted by the motor $M$, then the switch $K$ is adjusted, and then the additional voltage is input. 


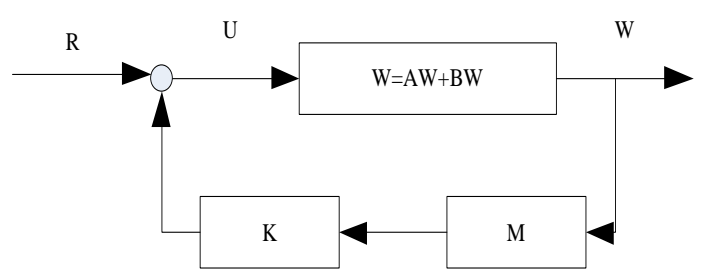

Figure 5. Circuit connection mode.

The circuit connection mode was divided into two types, namely, series and parallel. For the $\mathrm{f}$ series mode, the switch tube $Q_{1}$ was controlled using a PWM wave with duty cycle $D$ to achieve the effect of alternating conduction or cut-off. $L$ and $C$ filters were then used to obtain a stable DC output voltage $U_{0}$ on the load $R$. This circuit was a step-down circuit and an output voltage less than $36 \mathrm{~V}$ could not be achieved [24]. The parallel switching circuit was a step-up circuit. When the switch was turned on, the inductor started to store energy, and when it reached the cut-off time, the inductance energy started to output. Therefore, standard voltage could be achieved as long as the inductance winding was reasonable, and the output voltage $U_{0}$ presented a continuous smooth characteristic.

\section{Software Design of the Intelligent Supply Chain Information System}

\subsection{Software Flow Design of the Intelligent Supply Chain Information System}

The main equipment on the terminal to be initialized included the system timer, GPIO (General-purpose input/output) port, SPI (Serial Peripheral Interface), UART, and I2C (Inter-Integrated Circuit). The system tick timer was configured to improve intelligence and its terminal was set to $1 \mathrm{~ms}$. Then the interrupt processing function was set up to 1s. Finally, the first collected information was displayed on the LCD screen of the $\mathrm{M}_{0}$ terminal. The main program was polled for judgment. In the absence of external interruption, environmental data acquisition and $\mathrm{M}_{0}$ terminal LCD screen data display was mainly implemented. Then, the data was sent to the $\mathrm{A}_{8}$ server [25]. When an external RFID (Radio Frequency Identification) swipe card was used, other data were collected normally. The RFID interrupt function also collected and checked the data of the magnetic card data and sent it to the $\mathrm{A}_{8}$ server. When Zig Bee received data interruption, other data were collected normally. The interrupt handling function of the Zig Bee received the instructions sent by the $\mathrm{A}_{8}$ server and executed different instructions.

The software design of an intelligent supply chain information system should pay attention to the processing of serial interface and optical fiber interface data. The main task of the serial interface was to detect whether the serial interface received data. If the serial interface received the data, in order to improve the stability and anti-interference ability of the system, the data was first split. Along packet was split into several short packets. The initial identification, check code, and end identifier were added for each packet to form a data frame. The transmission of the next data frame was carried out after the correct transmission of each data frame. After the data frame was formed, the data was modulated by MCU (Microcontroller Unit) and sent to the optical fiber interface to send out the data [26]. The main task of the optical fiber interface was to detect whether the optical fiber interface received data. If the optical fiber interface received data, first the data frame format was verified. If the format was correct, the valid data was extracted to reconstitute the complete package. The data packet was then transmitted from the serial interface to complete the data transmission from the optical fiber interface to the standard serial interface.

The intelligent supply chain software flow of this system is shown in Figure 6. 


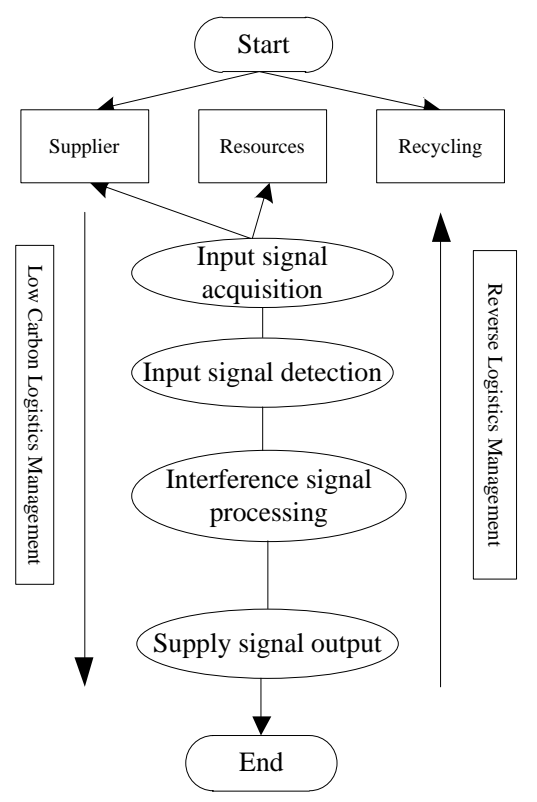

Figure 6. Intelligent supply chain software flow.

The software algorithm was implemented through a complex four step operation.

(1) Input signal acquisition. Asymmetric information theory can run through the whole software algorithm and plays an important role in analyzing the internal information of the supply chain. Chaotic data and supply data must have the same initial conditions when they pass through the chaotic system. Otherwise it is difficult to achieve simultaneous reception and transmission [27]. When the asymmetric information was the same, the software was reset. The chaotic data signal and the supply data signal were reset at the same time and sent to the next unit. When the asymmetric information was different, the subsequent contents would not be carried out. It was necessary to input the supply data signals to the intelligent supply chain again through system initialization.

(2) Input signal detection. Iterative detection of supply data signals was carried out through a NAND (Not AND) Flash and SDRAM device. The iteration cycle was usually 10-15 times. Each iteration result was fed back to the detection system as the next initial value until the function result was consistent with the result of its own compound function, and the iterative detection could be ended.

(3) Interference signal processing. A speech digital communication system was established by using the chaotic sequence after iteration, and the sending end and the receiving end were encrypted, respectively.

(4) Supply signal output. If it met the standard, the cipher was processed and the result would be displayed. If it did not meet the standard, the plaintext data were displayed.

Through the above process, the software was designed to ensure that the supply data signal system could work steadily. When software is supplying information, we should pay attention to the way of connection and the connection position in the Internet of Things. The result of the terminal node is fed back to the map. In this way, the staff can better grasp the working state of the supply chain from the overall situation. Since the data of supply information will change with time, it is necessary to establish a time base axis. When supplying certain data, the changes of data in a period of time should be recorded and mapped. The causes of the changes should be analyzed to prevent possible problems in time [28].

The intelligent supply chain software was also equipped with real-time monitoring equipment. The biggest advantage of this is to detect the abnormality of the system in time. Once the staff find that 
the data of a node are very different from that of other nodes, it is necessary to check whether the node is abnormal. If there is a serious abnormality in the supply data, it is necessary to activate the alarm device and take prompt measures.

\subsection{Software Algorithm Design of the Intelligent Supply Chain Information System}

The intelligent supply chain software algorithm was designed based on asymmetric information theory.

Assume node coverage is $n, n=M+N$, where $M, N$ are positive integers. According to the parity of $s$, the supply chain node coverage calculations are as follows:

$$
\mathfrak{R}_{\mathrm{p}}(R \mid n, s)=\frac{M \beta(s+1, n-s+1)+N \beta(s+a, n-s+b)}{M+N} .
$$

Extract $a$ and $b$ as asymmetric information axes to determine the symmetry of the supply information. On this basis, the method for judging the degree of symmetry is given as follows:

$$
E(x, y)=\sum_{u, v} w(n, s)[f(x+a),(y+b)],
$$

where $u$ represents symmetry information of the supply data base and $v$ represents symmetry information of the supply information. Symmetric information with $n$ points is decomposed into two symmetric information points. These two points are combined into $E(x, y)$ where $E(x, y)$ has $s$ points, that is, $w=0,1, \ldots, y$. So only the first half of the symmetric information is obtained by using Formula (2). To calculate all symmetry values, you must also apply the periodicity of the coefficients as follows:

$$
Y(x, y)=\sum_{u, v} w(u, v)\left[I_{x} u+I_{y} v\right]^{2}
$$

The $x$ and $y$ corresponding to the latter half of $I$ values is equal to the value corresponding to the first half of $s$ values.

In this way, the exact symmetric information of the supply chain was obtained.

\section{Structure Model Design of the Intelligent Supply Chain Information System}

The information structure and organizational structure of the supply chain affect each other and must be designed jointly. The centralization and networking of information structure promote the transformation of EPS (electric power steering)-based supply chain to EPS-based information network organization. The process of dividing the information hierarchy was in fact the classification (or grouping) of the supply chain network organization based on the EPS information node, and the influence and coordination ability of the supply chain members in the supply chain. The main basis of information level division included three aspects: The relationship among supply chain members, the importance of supply chain members, and the integration of information system.

In Figure 7, M is the information system, D is the enterprise partner, and the number of supply chain information levels is represented by the number of members of the supply chain. Members of the same information system had access authority. The closer the EPS node was, the closer the supply chain members were. The relationship of EPS-based supply chain members could be divided into four layers, namely, strategic corporation partner, important corporation partner, ordinary corporation partners, and electronic connections. The importance of the supply chain members determined the location of the information level of each supply chain member. In Figure 7, the closer the EPS node, the higher the importance of the supply chain members. The importance of supply chain members in the supply chain was determined by their influence in the supply chain [29]. Through the analysis of information structure and organizational structure based on the EPS supply chain, the application of 
EPS in the supply chain promoted the centralization and networking of the information structure in the supply chain.

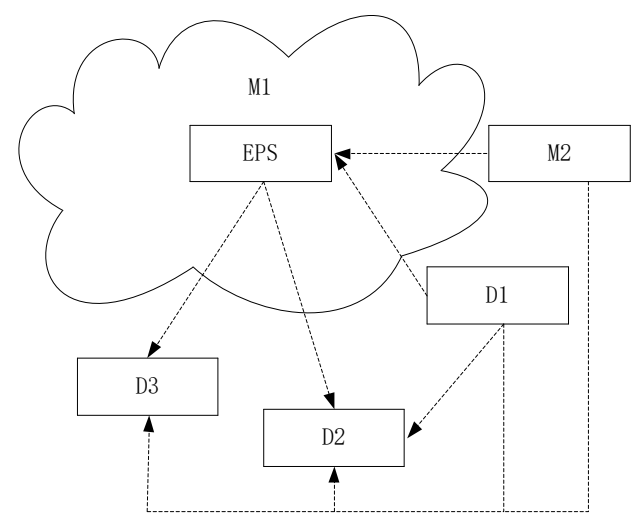

Figure 7. Structure model of intelligent supply chain information system.

The supply chain is a broad organization consisting of several independent traditional organizations, and the boundaries between traditional organizations will exist for a long time. But the organization boundary is gradually blurred because of the centralization and networking of the information structure, which promotes the flattening, networking, and dynamic virtualization of the organization structure of the supply chain. Therefore, the application of EPS in the supply chain first affects the information structure of the supply chain. The organizational structure of supply chain is influenced through the information structure, that is, the information structure of the supply chain affects the organization structure [30]. On the other hand, the supply chain network organization structure, which is formed to adapt to the complex and changeable market environment, also needs the channels and ways of information collection, processing, and transmission. The centralized and networked information structure based on the EPS supply chain can establish such information collection, processing, transmission channels and ways, that is, the structure of the supply chain requires adapting to the information structure.

Combining the above analysis and the definition of the information structure and organization structure of the supply chain from the generalized organizational perspective, we think that the relationship between the information structure and the organizational structure of the EPS supply chain is as follows.

(1) Information structure is an important part of the organization structure.

(2) Information structure and organizational structure affect each other and must be designed jointly.

\section{Experimental Research}

To verify the performance of the designed intelligent supply chain information system based on Internet of Things technology under asymmetric information, the IoT intelligent supply chain information system and the traditional supply chain system under asymmetric information were selected. Information was provided simultaneously for the two systems, the supply results were tested, and comparative experiments were conducted.

\subsection{Experimental Parameters}

The experimental parameters are shown in Table 2. 
Table 2. Experimental parameters.

\begin{tabular}{cccccc}
\hline Category & $\mathbf{8 2 7 5 1 E B}$ & $\mathbf{8 2 7 5 1 E I}$ & $\mathbf{8 2 7 5 1 E J}$ & $\mathbf{8 2 7 5 1 E V}$ & $\mathbf{8 2 7 5 1 E T}$ \\
\hline Code & ophir & tekor & hartwell & zoar & kawela \\
Port rate & 2 Gbps & 4 Gbps & 12Gbps & 3 Gbps & 4 Gbps \\
Port & PCIE & VD & REWD & HFHF & PRFE \\
Number of & 2 & 7 & 5 & 1 & 3 \\
interfaces & & & & & \\
Interface rate & 3 GT/s & 6 GT/s & 1 GT/s & 4 GT/s & 5 GT/s \\
MSI & Support & Nonsupport & Support & Nonsupport & Support \\
MSI-X & UBA & DWD & ERE & FGEST & AXXS \\
TX Queue & EDC25 & UTY & YTD & KUN & YER \\
RX Queue & DFV & DFHY & HD & DFGS & AWXD \\
RSS Queue & MBD & KUY & BCJ & SY & ASDFC \\
NC-SI & 4 & 3 & 2 & 9 & 0 \\
VMDq Queue & Nonsupport & Support & Support & Support & Nonsupport \\
VMDq & MCD & JTR & KYRS & ESG & JTEH \\
iSCSI & YEU & JYJ & DSSG & JRJ & JKD \\
FCOE & EEX11 & EEX75 & EEX49 & EEX35 & EEX7 \\
\hline
\end{tabular}

\subsection{Experimental Process}

The experiment was carried out based on the parameters set above.

(1) In order to ensure positioning accuracy, considering the positioning error, a $500 \mathrm{~m} \times 500 \mathrm{~m}$ square area was selected as the node deployment area. All nodes were randomly distributed in this area.

(2) It was assumed that the total number of nodes in the supply network was 300, which includes the unknown nodes and the anchor nodes. The number of the anchor nodes was 200. Because of the limited energy emitted by wireless sensors, the communication radius of nodes was generally around $10 \mathrm{~m}$.

(3) MATLAB simulation software was used to locate the number of unknown nodes other than anchor nodes. The ratio of the number of localizations to the total number was recorded. The unknown node recorded the number of data packets sent from each anchor node, waited until the positioning time was over, and calculated the ratio of the number of successfully located nodes outside the anchor node to the total number of unknown nodes. Due to uncertainties, there will be errors in the positioning process. The allowable measurement error is $0-30 \%$ of the real distance, which was randomly distributed, so as to ensure that the localization value is close to the optimal result.

The practical application results of the two supply chain systems were compared from the two aspects of supply data quantity and supply precision.

\subsection{Experimental Results and Analysis}

The experimental results were obtained as follows.

\subsubsection{Supply Data Information of the Two Systems}

From Figures 8 and 9, it can be seen that, in the $500 \mathrm{~m} \times 500 \mathrm{~m}$ square node area deployed in the Internet of Things, the data can be supplied by the proposed system and the traditional system. However, the data supplied by intelligent supply chain information system was much more than that of the traditional supply chain system. The traditional supply chain system supplied only 20 data nodes with low coverage, while the intelligence supply chain information system supplied up to 80 data nodes. The node coverage was four times that of the traditional systems, and the node coverage rate was very high. 


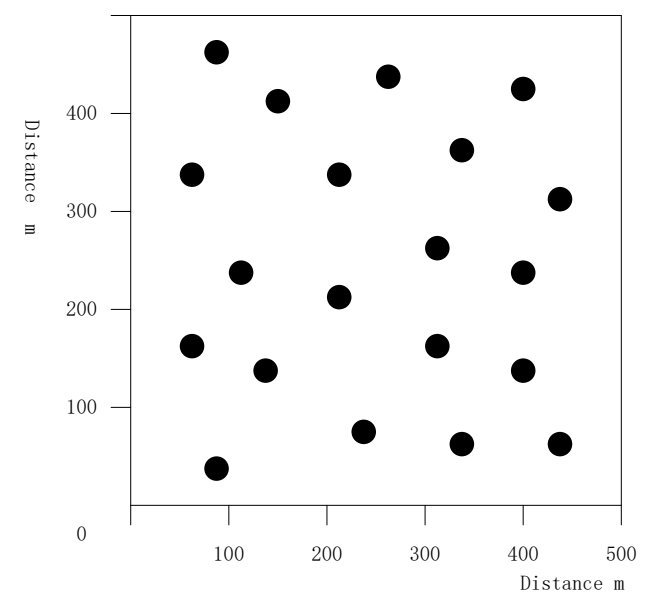

Figure 8. Information supplied by traditional system.

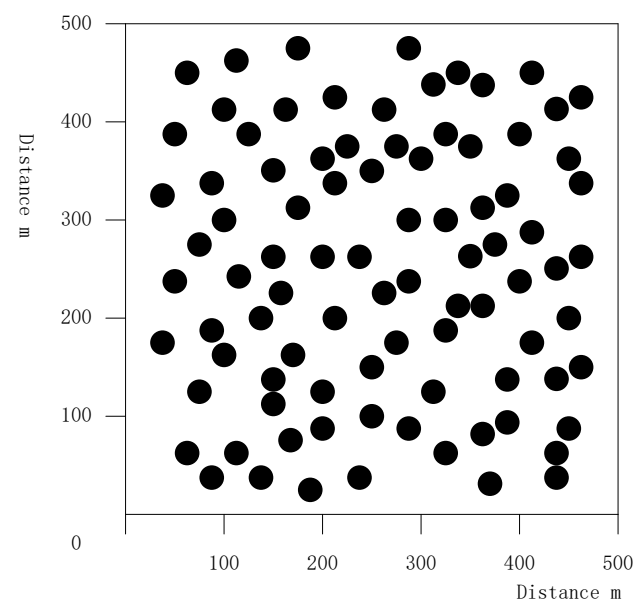

Figure 9. Information supplied by the proposed system.

\subsubsection{Operational Energy Consumption Comparison}

As shown in Figure 10, the operation energy consumption of the system was about 5\%, while the operation energy consumption of the traditional system was about $36 \%$, which fully proves the superiority of the system.

\subsubsection{Experimental Results of Supply Precision}

From Figure 11, it can be seen that, the more the number of data nodes supplied, the lower the supply capability of the system. However, the supply capability of intelligent supply chain information system was much more than that of the traditional supply chain system. When the number of data nodes was 20, the supply precision of the traditional supply chain system was $59 \%$, and the supply precision of the intelligent supply chain was $74 \%$. When the number of data nodes was 40 , the supply precision of the traditional supply chain system was $43 \%$, and the supply precision of the intelligent supply chain was $68 \%$. When the number of data nodes was 60 , the supply precision of the traditional supply chain system was $34 \%$, and the supply precision of the intelligent supply chain was $65 \%$. When the number of data nodes was 80 , the supply precision of the traditional supply chain system was $20 \%$, and the supply precision of the intelligent supply chain was $61 \%$. When the number of data nodes was 100, the supply precision of the traditional supply chain system was $15 \%$, and the supply precision of the intelligent supply chain was $56 \%$. When the number of data nodes was 120 , the traditional supply chain system was basically unable to supply, but the supply precision of the intelligent supply chain was still as high as $48 \%$. 


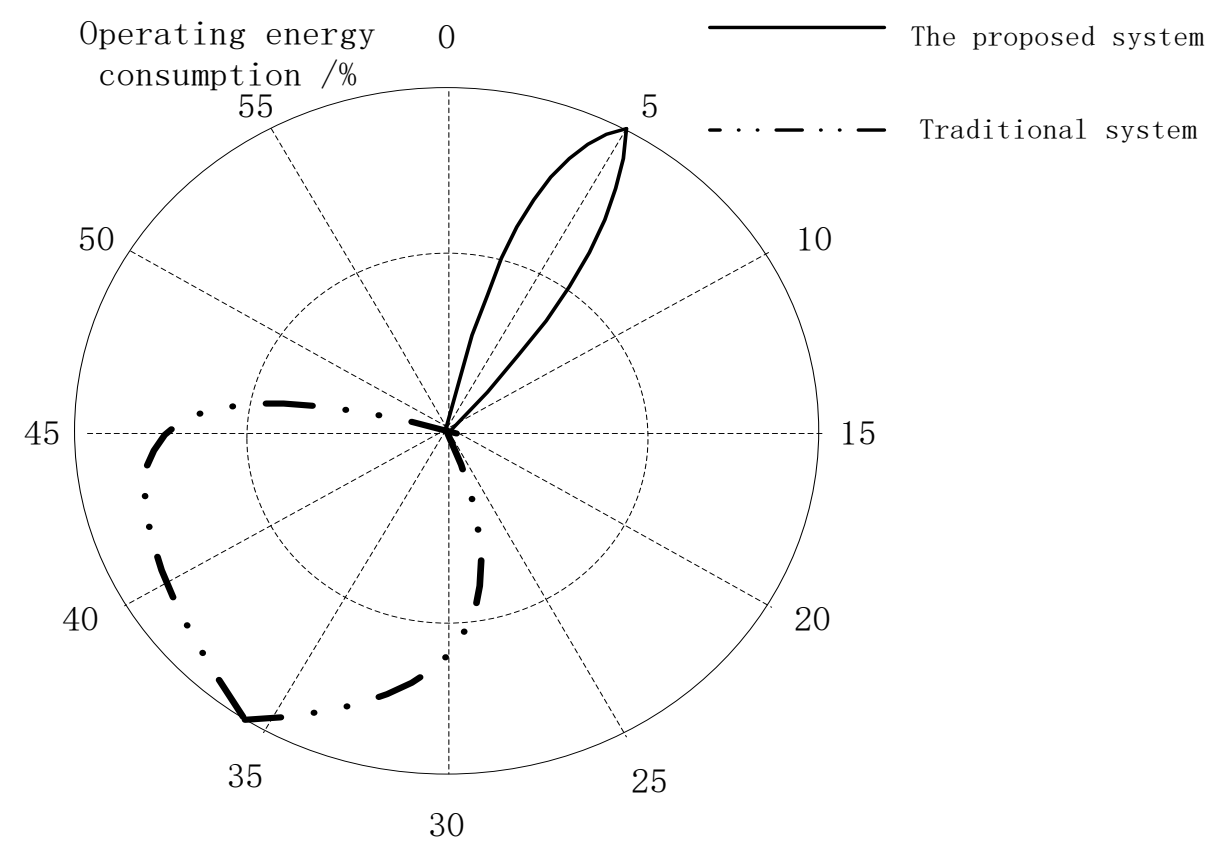

Figure 10. Operational energy consumption comparison chart.

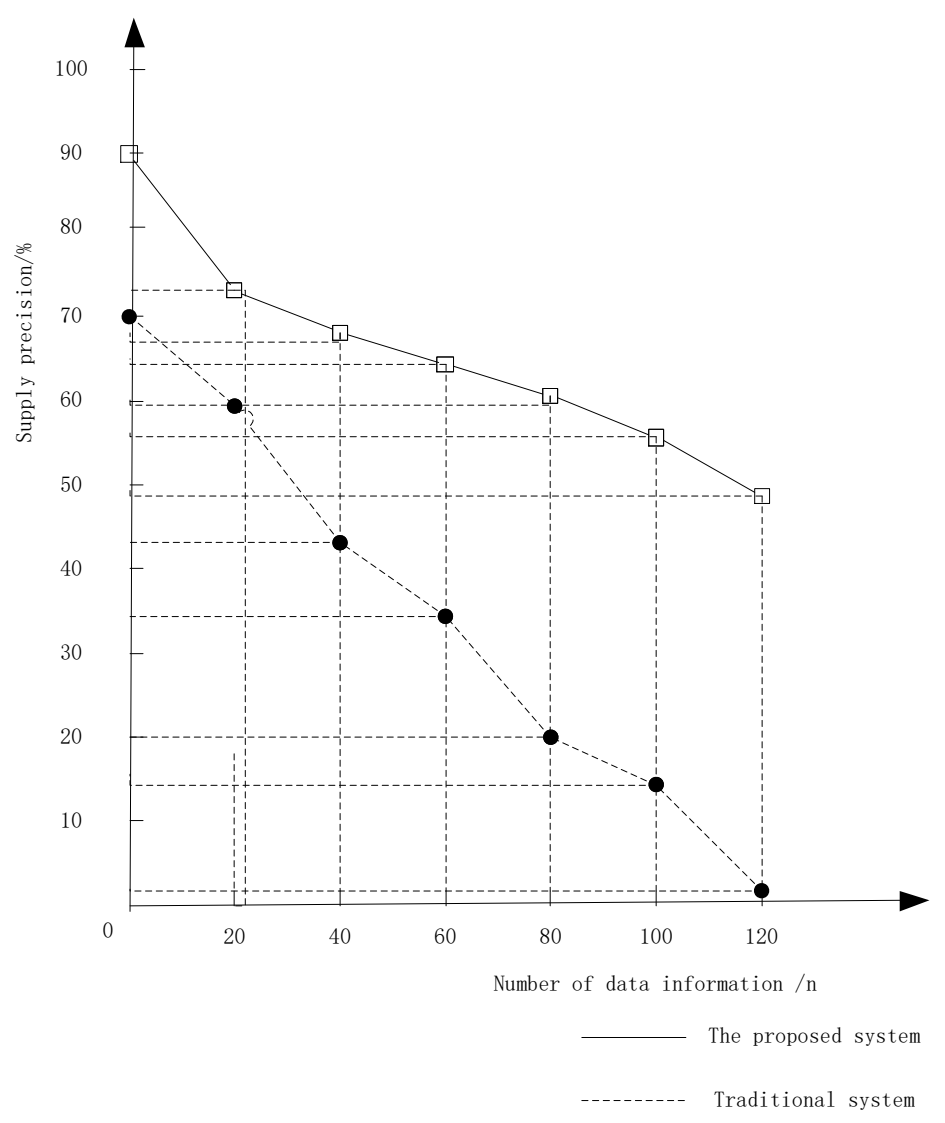

Figure 11. Experimental results of supply precision.

\subsection{Experimental Conclusions}

Based on the above experimental results, the following experimental conclusions were obtained.

(1) Conclusions of the first group of experiments. The supply capability of the intelligent supply chain information system is four times that of traditional supply chain system. In the same 
network monitoring area, the intelligent supply chain information system can supply up to $80 \%$ of the data nodes. For some stealthy data nodes, the intelligent supply chain information system can still be able to supply, but the traditional supply chain system can only supply $20 \%$ of the data nodes.

(2) Conclusions of the second group of experiments. With the increase of the number of supply data nodes, the supply precision of all kinds of supply systems will show a certain shortage, but the shortage of the traditional supply chain system is more obvious. When the number of supply nodes is more than 100, the traditional supply chain system technology cannot supply accurately, but the precision of the intelligent supply chain information system can be maintained over $50 \%$.

To sum up, the intelligent supply chain information system researched in this paper is far superior to the traditional supply chain system for network data supply capability. For supply effectiveness and supply accuracy, intelligent technology, information sharing technology, and Internet of Things technology have shown great advantages.

With the support of the supply chain information system, the Internet of Things information is delivered to the user accurately and on time. Therefore, the value of the supply chain information system is the difference between the optimal result of the total cost of the manufacturer's inventory under the condition of non-information system and the optimal result under the condition of information system. When there is a contradiction between accuracy and timeliness, enterprises must first improve the accuracy of sharing information, and then enhance the timeliness of sharing information. This strategy is especially effective in the case of high-demand historical relevance. Meanwhile, the establishment of an information system to support information sharing can synchronously enhance the accuracy and timeliness of the information. Finding the optimal investment volume through supply chain information system is not a case of the more the better. We need to focus on the positive correlation of demand information in a time series. If there is no time correlation for demand information, information sharing will lose value, and information system is also difficult to create extra value.

A supply chain system can improve information accuracy and information timeliness to reduce the total cost. However, in practical application, when the enterprise does not apply the information system, information accuracy and information timeliness are often both not achieved. The traditional mode of information transmission and summary is by the manual way. When the amount of information is large, in order to ensure the timeliness of the information, the summary of the information needs to be completed in a relatively short time, which inevitably leads to data errors. If a company requests to check the information carefully and repeatedly, it will easily delay the time of information sharing. Therefore, it is impossible to ensure the accuracy and timeliness of information in manual mode. Contrary to manual mode, links of intelligent information systems can automatically aggregate and deliver orders. For each transaction, the manufacturer will immediately obtain information on the number and type of products traded. Therefore, no matter which nodes need to make production decisions, manufacturers have completely accurate and completely timely information, which is also the additional value attached to the designed intelligent information supply chain system.

\section{Conclusions}

With the rapid integration of information and industrialization, the modern remanufacturing technology urgently needs to collect and classify multi-source information in the remanufacturing process, and monitor, analyze, predict, and control the production process of remanufacturing products. In this paper, for the problems in a traditional supply chain, a new intelligent supply chain information service system was constructed by using the Internet of Things technology and asymmetric information theory. Through hardware and software design, intelligent manufacturing of things was realized. It can not only improve the systematization, standardization, automation, and scientificalization of information management in remanufacturing enterprises, so as to obtain better economic benefits and enhance the core competitiveness of enterprises, but also effectively save resources. The research work of this paper has certain guiding significance for the future development of intelligent information 
supply chain system, and hopes to provide help for future scholars to research the relevant aspects of the information supply chain.

Author Contributions: Conceptualization, Y.Z. and X.X.; methodology, Y.Z.; software, X.X.

Funding: This research received no external funding.

Conflicts of Interest: The authors declare no conflict of interest.

\section{References}

1. Bedowr, N.S.; Yahya, R.B.; Farhan, N. Structural characterization of copper (ii) tetradecanoate with 2, 2'-bipyridine and 4, 4'-bipyridine to study magnetic properties. J. Saudi Chem. Soc. 2018, 22, 255-260. [CrossRef]

2. Chen, Y.; Yang, X.; Liu, H.L. An exponentially modified Gaussian fitting peak seeking algorithm to process FBG sensing signals. Spectrosc. Spectr. Anal. 2017, 36, 1526-1531.

3. Cheng, C.; Liu, Z.; Guo, Z.; Debnath, N. Waste-to-energy policy in china: A national strategy for management of domestic energy reserves. Energy Sources Part B-Econ. Plan. Policy 2017, 12, 925-929. [CrossRef]

4. Huang, Z.W.; Wang, S.X. Design of asymmetric distribution system for task network load of IoT nodes. Sci. Technol. Eng. 2017, 17, 268-273.

5. Kai, Z.; Shen, J.; Yao, X. A three-echelon supply chain with asymmetric information under uncertainty. J. Ambient Intell. Humaniz. Comput. 2018, 18, 1-13.

6. Gou, J.L. The application of the Internet of Things technology in the intelligent manufacturing of ships. Ship Sci. Technol. 2017, 43, 49-51.

7. Gong, Y.Z.; Liu, F.; Pang, R.Q. Supply chain finance logistics supervision based on Internet of Things technology. China Sci. Technol. Forum 2017, 5, 131-136.

8. Grubisic-Cabo, F.; Nizetic, S.; Coko, D.; Kragic, I.M.; Papadopoulos, A. Experimental investigation of the passive cooled free-standing photovoltaic panel with fixed aluminum fins on the backside surface. J. Clean. Prod. 2018, 176, 119-129. [CrossRef]

9. He, Y.G.; Zhang, W.L. Research on information sharing mode of chemical supply chain based on Internet of Things technology. Logist. Technol. 2017, 35, 130-135.

10. Huang, T.; Yang, R.; Huang, W.; Huang, Y.; Qiao, X. Detecting sugarcane borer diseases using support vector machine. Inf. Process. Agric. 2018, 5, 74-82. [CrossRef]

11. Jiang, W.Z. Research and design of agricultural information intelligent monitoring system based on Internet of Things technology. Ind. Des. 2016, 45, 174-176.

12. Jin, H.Y.; Ma, J.G.; Su, Y. RTU efficient data transmission control method for narrowband asymmetric channel. Electron. Meas. Technol. 2017, 23, 170-174.

13. Kendra, P.E.; Montgomery, W.S.; Niogret, J.; Tabanca, N.; Owens, D.; Epsky, N.D. Utility of essential oils for development of host-based lures for xyleborusglabratus (coleoptera: Curculionidae: Scolytinae) vector of laurel wilt. Open Chem. 2018, 16, 393-400. [CrossRef]

14. Li, H.P.; Chen, L.Y.; Lu, Y. A key management scheme applicable to military Internet of Things. J. Ordnance Eng. Coll. 2017, 29, 30-33.

15. Liang, S.X.; Wang, Q. Industrial logistics cluster supply chain service platform for equipment manufacturing. Comput. Simul. 2017, 33, 242-245.

16. Ling, Z.L.; Qian, G.; Luo, Y. Intelligent water network automation measurement monitoring and management system based on Internet of Things. Water Supply Drain. China 2017, 42, 115-119.

17. Mai, M.T.; Hai, L.L.; Maimaiti, H. Supply chain association based on Internet of Things RFID Technology. Logist. Eng. Manag. 2016, 38, 62-63.

18. Pradeep, S.R.; Srinivasan, K. Alleviation of oxidative stress-mediated nephropathy by dietary fenugreek (trigonellafoenum-graecum) seeds and onion (allium cepa) in streptozotocin-induced diabetic rats. Food Funct. 2018, 9, 134-148. [CrossRef]

19. Rodeiro-Guerra, I.; Hernandez-Ojeda, S.; Herrera-Isidron, J.; Hernandez-Balmaseda, I.; Padrón, A.S.; Olguin, S.; Alejo-Rodríguez, P.L.; Ronquillo-Sánchez, M.D.; Camacho-Carranza, R.; Menendez, R.; et al. Study of the interaction of an extract obtained from the marine plant thalassiatestudinum with phase $\mathrm{i}$ metabolism in rats. Rev. Int. Contam. Ambient. 2017, 33, 547-557. [CrossRef] 
20. Shan, C.L.; Ning, X.F.; Li, S.J. Design of quality safety traceability management system for pig farm based on Internet of Things technology. Manuf. Autom. 2017, 38, 1128-1214.

21. Singh, K.; Gupta, N.; Dhingra, M. Effect of temperature regimes, seed priming and priming duration on germination and seedling growth on American cotton. J. Environ. Biol. 2018, 39, 83-91. [CrossRef]

22. $\mathrm{Su}, \mathrm{J}$. Design and implementation of automobile supply chain logistics management system based on Internet of Things technology. Autom. Instrum. 2016, 28, 119-121.

23. Tomporowski, A.; Flizikowski, J.; Opielak, M.; Kasner, R.; Kruszelnicka, W. Assessment of energy use and elimination of $\mathrm{Co} 2$ emissions in the life cycle of an offshore wind power plant farm. Pol. Marit. Res. 2017, 24, 93-101. [CrossRef]

24. Wan, L.S.; Chen, L.; Zhang, L.L. Design of ownership transfer scheme based on supply chain environment. Comput. Eng. Des. 2016, 37, 1770-1776.

25. Wang, S.L.; Wang, Q.; Hu, Y.F. Research on information security of electric power asset management based on RFID. Electrotechnical 2017, 15, 00109.

26. Wang, W.; Wang, Y.; Xu, D.C. Research on intelligent campus information system based on Internet of Things technology. Comput. Netw. 2017, 42, 68-69.

27. Li, C.Z.; Xiao, P.F.; Feng, X.Z. Recognition of Snow Cover in Multi-temporal Mountain Areas with High Satellite No. 1 Satellite Data. Remote Sens. Inf. 2017, 32, 71-78.

28. Ye, X.R.; Shao, Q.; Xiao, R. Technology guide based on block chain, supply chain prototype system based on block chain. Intell. Contract Internet Things 2017, 35, 29-62.

29. Zhao, J.; Yang, J. Design and implementation of encryption module in multi-device communication of Internet of Things. Mod. Electron. Technol. 2017, 39, 69-72.

30. Zhu, Y.; Gan, G.H.; Deng, D. Research on security in key technology of blockchain. Inf. Secur. Res. 2017, 2, 1090-1097.

(C) 2019 by the authors. Licensee MDPI, Basel, Switzerland. This article is an open access article distributed under the terms and conditions of the Creative Commons Attribution (CC BY) license (http://creativecommons.org/licenses/by/4.0/). 